\title{
ON THE USE OF AN INFRA-RED CAMERA FOR THE MEASUREMENT OF TEMPERATURE IN FIRES OF VEGETATIVE FUELS
}

\author{
F. RINIERI ${ }^{*}$, J.-H. BALBI ${ }^{*}$, P-A. SANTONI ${ }^{*}$ \\ * Université de CORSE UMR 6134 Quartier Grossetti, BP 52, 20250 CORTE, France
}

\begin{abstract}
In this work, we propose an original methodology based on infra-red thermography to measure the temperature in the flames and embers of a fire of vegetation. An infra-red camera provides digital levels in output that can be used to retrieve the temperature of the target. The method usually used to obtain this temperature follows a formalism resulting from the law of Planck. Both relationships were compared for static and spreading fires. The proposed approach provides better agreement with experiments than the classical method.
\end{abstract}

\section{Introduction}

The long-term objective is to provide to operational fire protection fight, a simulator of fires. For that, it is necessary to have a simplified model of the propagation [1] (so that the computing time is much lower than the real time). Moreover, this model must be fixed and validated for real fires of ground. The most significant variable of state is the temperature (flame, vegetation), the measurement of this one in laboratory is carried out with a together of thermocouples [2]. On the other hand, for fires on a large scale, the measurement by thermocouples is not reasonably possible. We propose to use an infra-red camera to solve this problem.

The camera used in this work is a focal plane array (FPA) camera operating in the MIR band. This band is a part of the electromagnetic spectrum located from 3 to $5 \mu \mathrm{m}$. It was chosen for fire applications since for temperature of about $1000^{\circ} \mathrm{C}$, approximately one third of the radiated power is emitted in the MIR band. Furthermore, at that temperature the wavelength of maximum emission is $4 \mu \mathrm{m}$, which is in the centre of the MIR band. The acquisition card makes it possible to work on 128 or 256 points per line and column and gives matrices of 256X256 detectors (respectively $128 \times 128$ detectors) until a acquisition frequency of $25 \mathrm{~Hz}$. The digital levels are quantified with a 14-bit dynamic range (16384 digitals levels). The thermosignal acquisition is recorded on a computer. The digital level of a pixel is proportional to the radiant intensity emitted by the fire. The adjustable integration time of the camera, which can be set from 10 to $1000 \mu \mathrm{s}$, allows accommodating a wide range of flux levels. The integration time is the duration that the FPA is allowed to collect infrared photons. Thus, short integration times are used to measure thermal scenes with high temperatures, like fire presence phenomena, without saturation problems. The acquisition rate of the camera allows capturing up to 25 images per second. There are two main contributions to the infrared emission of a fire: that of the emitted gases (mainly $\mathrm{CO}_{2}$ and $\mathrm{H}_{2} \mathrm{O}$ in the flame) and that of the hot solid particles (embers). The use of specified filters, ahead of the detector of the infrared camera, allows focusing either on the combustion processes occurring in the gaseous phase (filter $4.2 \mu \mathrm{m}$ ) or on those occurring in the solid phase (filter $3.9 \mu \mathrm{m}$ ). The approach developed to obtain the temperature in flames is based on the assumption that a flame can be view as a grey surface body [3,4] with emissivity $\mathcal{E}$, $\phi$ is the view factor and with temperature $T$. The rate at which radiant energy is emitted by a surface element dS of the flame is (figure 1): 


$$
d R=\varepsilon \sigma T^{4} \phi d S
$$

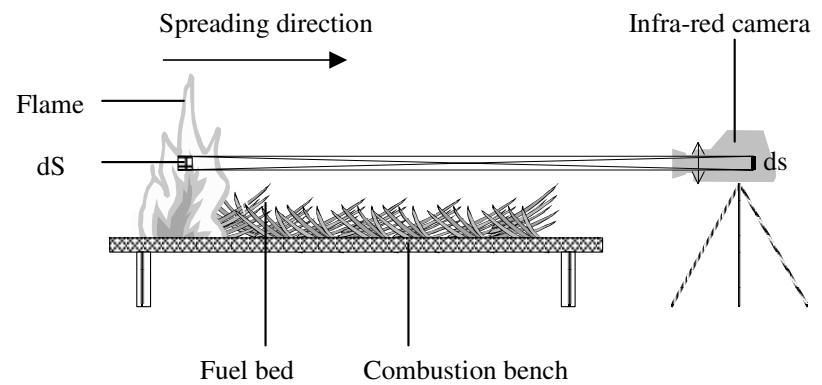

Fig. 1. Optical way of the radiation emitted by the flame

This radiant energy impinges the sensor matrix and gives finally a signal $d r$ proportional to $\mathrm{dR}$. Actually, the answer law of the camera (Figure 2) includes a shift with origin:

$$
\frac{d r}{d s}=\alpha \frac{d R}{d S}+N_{0}=\alpha \varepsilon \sigma T^{4}+N_{0} .
$$

This is why we assume that the digitals levels $\mathrm{N}$ of the camera and the temperature, $\mathrm{T}$ in the flame follow the relationship:

$$
N-N_{0}=a T^{4}
$$

We will see that parameter $a$, depends in a linear way on the distance camera-flame. To determine $N_{0}$, a system of two equations is solved by taking the maximum and the minimum digital level. A minimization criterion is then applied to identify $a$. By denoting $u=T^{4}$ and $y=N$, Eq. (3) is written in the functional form

$$
J(a)=\sum_{j}\left(a u_{j}+N_{0}-y_{j}\right)^{2} .
$$

By derivation at the point $a$, we have:

$$
a=\frac{\sum_{j} u_{j} y_{j}-\sum_{j} N_{0} u_{j}}{\sum_{j} u_{j}^{2}} .
$$

Eq. (3) was compared with the relation usually used, which follows a formalism resulting from the law of Planck. It was stated by Pajani [5] and then completed by Arconada et al. [6]. This relation is presented in the following form:

$$
N=\frac{A}{e^{\frac{B}{T}}-C}
$$

\section{Measurement of temperature in black body by infra-red camera}

Initially, Eqs. (3) and (6) are compared for a system of the type black body, the results obtained are presented (figure 2 ): 


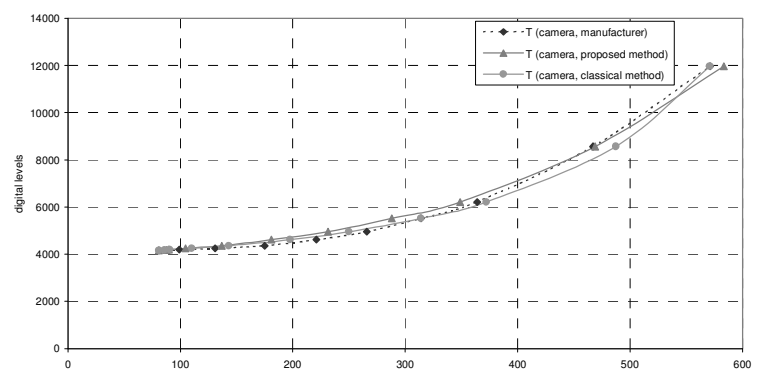

Fig. 2. Temperature given by the proposed and classical relations for a calibration curve obtained with a filter of $4.2 \mu \mathrm{m}$ and an integration time of $200 \mu \mathrm{s}$

The calibration curves displayed in this figure was obtained from a black body for temperature ranging from $81^{\circ} \mathrm{C}$ to $600^{\circ} \mathrm{C}$. A filter of $4.2 \mu \mathrm{m}$ and a time integration of $200 \mu \mathrm{s}$ were used for the camera. As a first stage of validation, we can note that results provided by both relations are in good agreement with the experimental data.

\section{Temperature measurement in static flame by infra-red camera}

The difficulties encountered in measurement by infra-red cameras were underlined by Pajani [7] and Balageas et al. [8]. They are related to the studied object, the experimental device, the optical way between the object and the camera, the camera calibration, the data processing and the Narcissi's purpose. By taking into account the recommendations provided in $[7,8]$, experimental fires were carried out with ethanol and vegetable fuels in a room closed without any air motion. Until now to measure the temperature of a flame or embers of the thermocouples were used [2]. They present of the advantages and the disadvantages. For fires of laboratory, measurement is simple and easy but for fires on a large scale it is more complicated. To solve this problem, we propose to use an infra-red camera. The thermocouples used for this study are of the thermocouple of type $\mathrm{K}$ (chromel-alumel) with an exposed junction. The wires of the thermocouples were $50 \mu \mathrm{m}$ in diameter. But they have a certain inertia compared to the infra-red camera, it is thus less precise

\subsection{Static flame of ethanol}

In these experiments, a cupel (diameter $6 \mathrm{~cm}$, depth $8.5 \mathrm{~mm}$, and wall thickness $1.5 \mathrm{~mm}$ ) was filled with $0.95 \mathrm{~g}$ of pure ethanol (95-96 vol\%). The cupel was placed on a large bench which allowed lateral inflows of air. The resulting height of the flame was about $20 \mathrm{~cm}$. The thermocouple were placed at different heights in the flame. The infra-red camera was placed at $80 \mathrm{~cm}$ from the cupel. A filter for $\mathrm{CO}_{2}$ (filter $4.2 \mu \mathrm{m}$ ) and an integration time of $50 \mu \mathrm{s}$ were used. An infra-red image of the flame is displayed in (figure $3 a$ ).

a)

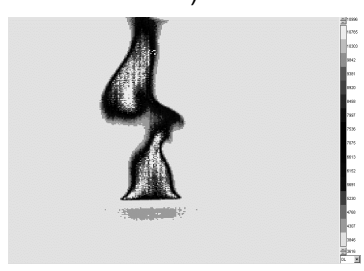

b)

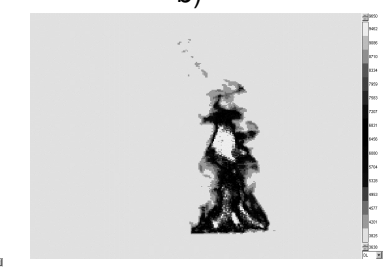

c)

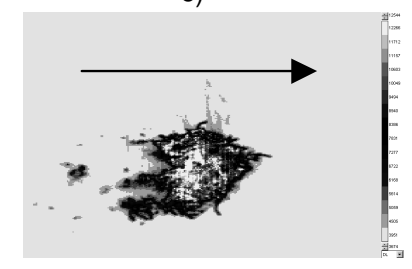

Fig. 3a-c.Infra-red images of static flames of a) ethanol and b) Pinus pinaster needles c) a fire front spreading across a bed of Pinus pinaster needles 
From an experiment, the parameters $A, B, C$, a and $\mathrm{N}_{0}$ were identified following the method proposed in the previous section. A comparison between the temperature given by Eqs (3) and (6) and the temperature provided by thermocouples is presented on (figure $4 \mathrm{a}$ and $4 \mathrm{~b}$ ) at two heights in the flame.

a)

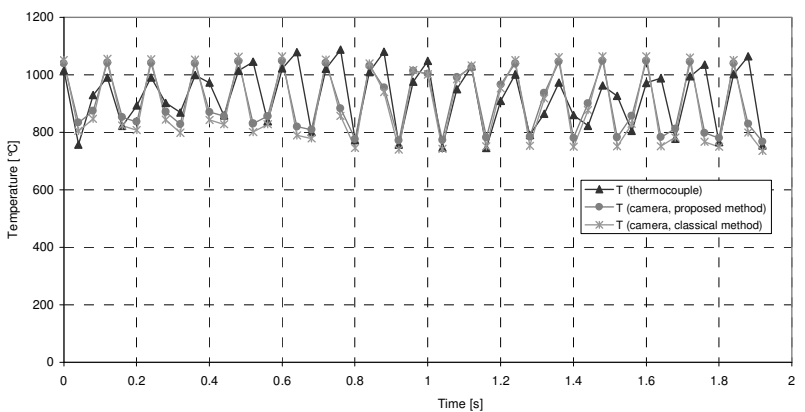

b)

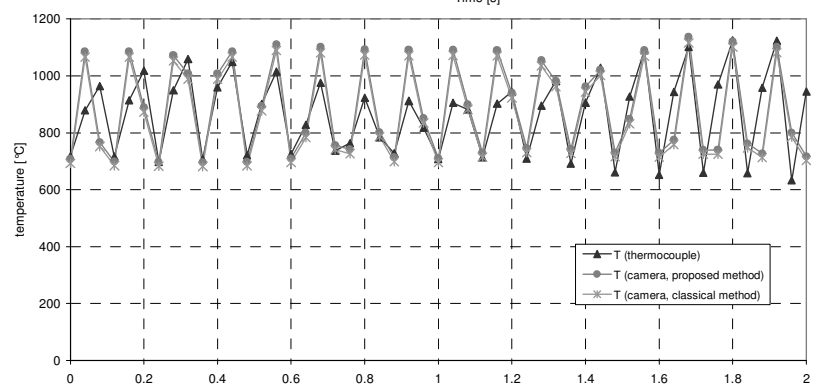

Fig. 4a-b. Temperature measured by thermocouple and infra-red camera for a flame of ethanol, at two heights a) $5.8 \mathrm{~cm}$ and b) $3.2 \mathrm{~cm}$

We can notice that infra-red camera seems adapted for the measurement of temperature in this flame because the frequencies of pulsations are encountered in the flame, the maximum and minimum temperatures are translated by the two equations. Eq (3) is thus validated for various positions in the flame. It seems that the parameters are constant along it.

\subsection{Static flame of Pinus pinaster needles}

In these experiments, the fuel used is Pinus pinaster needles. It was dehydrated 24 hours at a $60^{\circ} \mathrm{C}$ temperature. Since the needles partially re-hydrated during their removal from the oven and the ignition, a sample of needles was loaded to evaluate the fuel moisture content before each run. It was found that the needles were conditioned to a moisture content of less than $3 \%$. The fuel was spread as evenly as possible on the combustion bench in order to obtain a homogeneous layer, with a load of approximately $2 \mathrm{~kg} / \mathrm{m}^{2}$. Ignition was performed with ethanol and the resulting flames had a height of about $45 \mathrm{~cm}$. The temperature in the flame was measured with thermocouples located above fuel as in the case of the ethanol flame. The configuration of the infra-red camera remained unchanged. Such flames possess a higher number of frequencies than encountered in the ethanol flame [9], as depicted in (Figure $3 a$ and $3 b$ ), corresponding respectively to infra-red images of flames of alcohol and Pinus pinaster needles. From an experiment, the parameters $A, B, C, a$ and $N_{0}$ were identified following the method proposed in the previous section. A comparison between the temperature given by Eqs (3) and (6) and the 


\section{http://dx.doi.org/10.21611/qirt.2006.011}

temperature provided by thermocouples is presented on Figure 5a. To validate, our method, the fuel load increases, the flame height increases hence the infra-red camera receives more incident radiation. For a fuel load of $4 \mathrm{~kg} / \mathrm{m}^{2}$, the flame was about $53 \mathrm{~cm}$ high. The results are presented in (figure 5).

a)

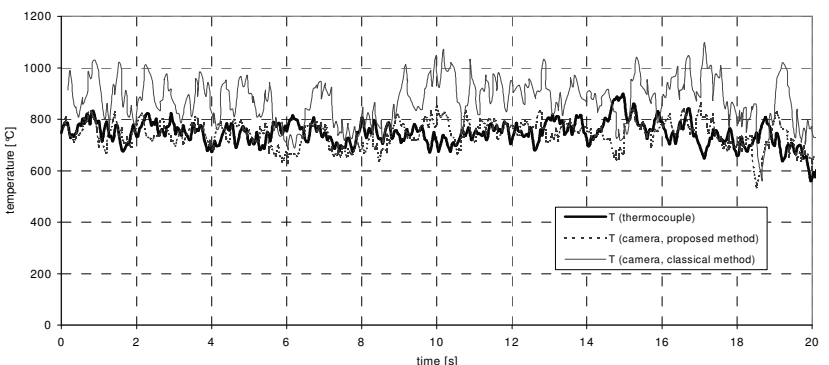

b)

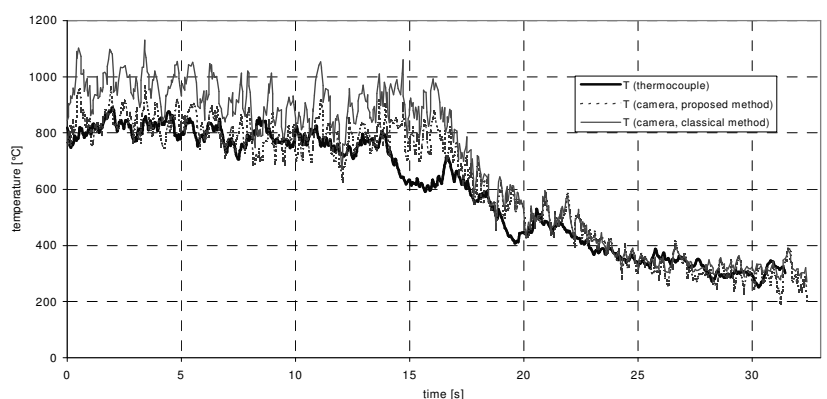

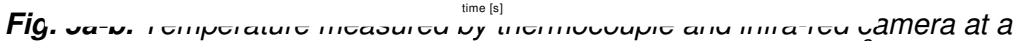

height of $4 \mathrm{~cm}$ for flame of Pinus pinaster needles with loads of a) $2 \mathrm{~kg} / \mathrm{m}^{2}$ b) $4 \mathrm{~kg} / \mathrm{m}^{2}$

We can observe in (figure 5) that the temperature provided with our relation is close to the temperature measured by thermocouple for both loads. Eq (3) overestimates the temperature, however. The decrease of temperature with decreasing fuel is provided by both Eqs (3) and (6) (Figure 5b).

\subsection{Temperature measurement in a spreading fire front by infra-red camera}

This section is devoted to test the method of measurement of temperature by infra-red camera in the case of a fire front spreading across a litter of Pinus pinaster needles. This area contains both gas and solid phases. In these experiments, the configuration of the infra-red camera was changed: a filter flame (filter $3.9 \propto \mathrm{m}$ ) and an integration time of $50 \mu$ s were used. The experimental apparatus was composed of an air-entrained concrete plate $(1.2 \mathrm{~m}$ long and $0.5 \mathrm{~m}$ wide) protected by sand. Pure oven-dried pine needles were spread on a portion $(0.7 \mathrm{~m}$ long and $0.4 \mathrm{~m}$ width) of the total area of the combustion table to give a homogeneous structure, representative of a typical layer found in Corsican forests with a load of approximately $0.5 \mathrm{~kg} / \mathrm{m}^{2}$ on a dry basis. The depth of fuel was approximately $4 \mathrm{~cm}$, giving a bulk density of $12.5 \mathrm{~kg} / \mathrm{m}^{3}$. Experiments were performed to observe the spread of the fire under no slope and without any wind for line-ignition fires. For these, a line was ignited using alcohol at one small edge of the fuel-bed. Thermocouples were located in the litter along its main axis from the line ignition. The infra-red camera was placed at $2 \mathrm{~m}$ from the fuel bed, parallel to the fire front and at a height of 1,90 meters. It was tilted with $30^{\circ}$ in order to observe the bed from above. An infra-red image of the Pinus pinaster litter in combustion is presented in (figure 
3c). Parameters $A, B, C, a$ and $N_{0}$ were identified from an experiment far enough from the ignition line for the fire to achieve a stable spread-rate and flame shape. The constant spread-rate was confirmed by using the temperatures recorded by the thermocouple located in the litter along its main axis. The results obtained by the conversion of the digital levels into temperature are provided in (figure 6).

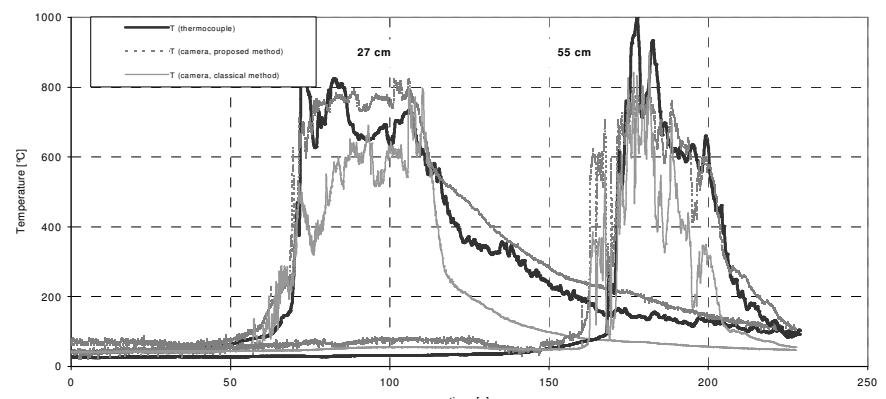

Fig. 6. Temperatures measured by thermocouples and infra-red camera at 27 $\mathrm{cm}$ and $55 \mathrm{~cm}$ away from the ignition line.

We can note that the temperatures obtained with Eq. (3) are in good agreement with those recorded by thermocouples, during the pre-heating and cooling stages. The temperature given by Eq. (3) seems slightly over-estimated during part of the combustion while it seems underestimated by Eq. (6). In fact, the overestimation is due to the non thermal equilibrium between gas and fuel solid phases, while flaming combustion. The thermocouples are located in the litter and they measure the gas temperature. The camera focuses on the fire front and more precisely on the solid phase with the chosen filter. The temperature of the solid phase is higher than the gas one [10] over this stage. This result is depicted by Eq. (3). However, Eq. (6) fails to predict this tendency. Eq. (3) is more reliable in the three stages than Eq. (6) for a spreading fire front.

The proposed method is very robust since the values of the parameters are unchanged for a given fuel. They do not depend on the measurement point in the flame. Moreover, this relation possesses only two parameters, whereas the classical one requires to identify three parameters.

\section{Effect of the distance camera-flame on the measurement method}

To note the influence of the distance camera-flame, various experiments are carried out to $2 \mathrm{~m}, 3 \mathrm{~m}, 4 \mathrm{~m}$ and $5 \mathrm{~m}$. The infra-red images of the flame are presented in (figures 7 ).

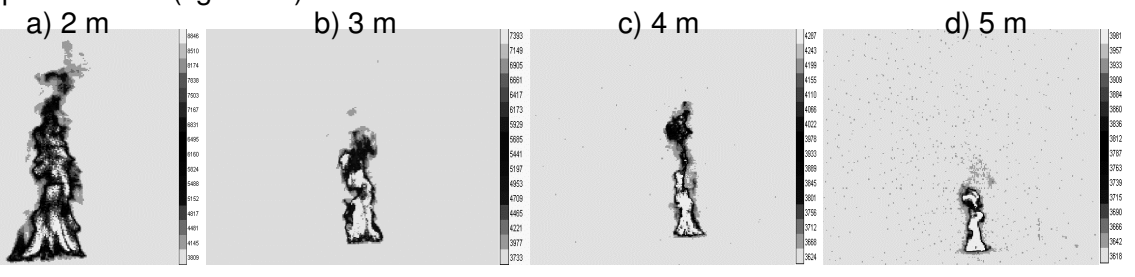

Fig. 7a-d. Infra-red images of static flame of Pinus pinaster needles a) $2 m$, b) $3 m, c) 4 m, d) 5 m$

We note that there is a fall of the digital levels according to the distance because the height of the flame decreases. The infra-red camera thus receives less flow. We will examine the evolution of the parameters of our model Eq. (3) according 


\section{http://dx.doi.org/10.21611/qirt.2006.011}

to the distance This study showed that the parameter a decreases linearly according to the distance while $N_{0}$ remains constant. Eq. (3) becomes

$$
\left\{\begin{array}{l}
N-N_{0}=a T^{4} \\
a=a_{1} x+a_{0}
\end{array}\right.
$$

where $x$ represents the distance between the camera and the flame. For these experiments, the height of the flame was $53 \mathrm{~cm}$ for flame Pinus pinaster and $20 \mathrm{~cm}$ for flame ethanol. The infra-red camera was located at various distance from the fire and both filters were used. The parameters values are provided in Table 1.

Table 1. values of the parameters $a_{1}, a_{0}$ and $N_{0}$

\begin{tabular}{|c|c|c|c|}
\hline flame & filter & $a=a_{1} x+a_{0}$ & $N_{0}$ \\
\hline ethanol & $\mathrm{CO}_{2}$ filter $(4.2 \mu \mathrm{m})$ & $a=-1.41 \times 10^{-9} x+3.46 \times 10^{-9}$ & 2900 \\
\hline Pinus pinaster & $\mathrm{CO}_{2}$ filter $(4.2 \mu \mathrm{m})$ & $a=-1.09 \times 10^{-9} x+6.29 \times 10^{-9}$ & 3500 \\
\hline Pinus pinaster & Flame filter $(3.9 \mu \mathrm{m})$ & $a=-1.80 \times 10^{-9} x+1.34 \times 10^{-8}$ & 3500 \\
\hline
\end{tabular}

The improved relation was then tested with those values for different static and spreading flames, different distances and using both filters.

\subsection{Static flame of ethanol}

The experimental conditions are unchanged, except the infra-red camera is placed at various positions. The results presented in (figure 10).

a)
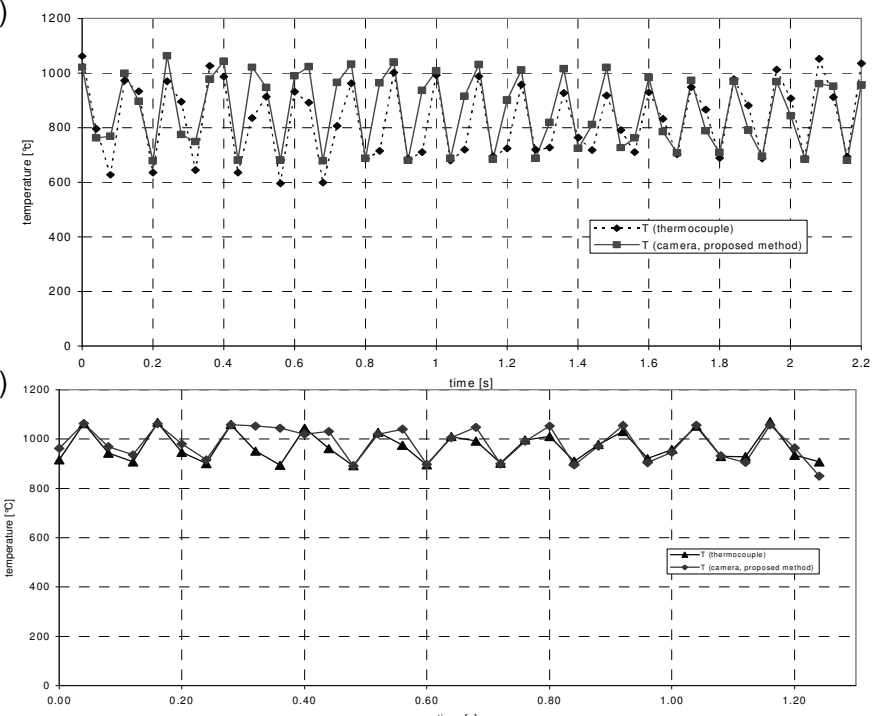

Fig. 10 a-b. Temperature measured by thermocouple and infra-red camera for a flame of ethanol at two distances a) $50 \mathrm{~cm}$ and b) $100 \mathrm{~cm}$

We note that the temperature measured by infra-red camera is similar temperature measured by thermocouple because the frequencies of pulsations are encountered in the flame, the maximum and minimum temperatures are translated by our model. 


\subsection{Static flame of vegetable fuels}

In this study, we will use three consbustibles: Pinus pinaster needles, Helichrysum italicum [11] and a Cistus ladaniferus. The experimental conditions are unchanged, except the infra-red camera is placed at various positions. An infra-red image of the flame of Pinus pinaster needles, Helichrysum italicum and Cistus ladaniferus is presented in the (figures $7 \mathrm{~b}, 12 \mathrm{a}$ and 13a). The results are presented in the (figures 11, 12b and 13b).

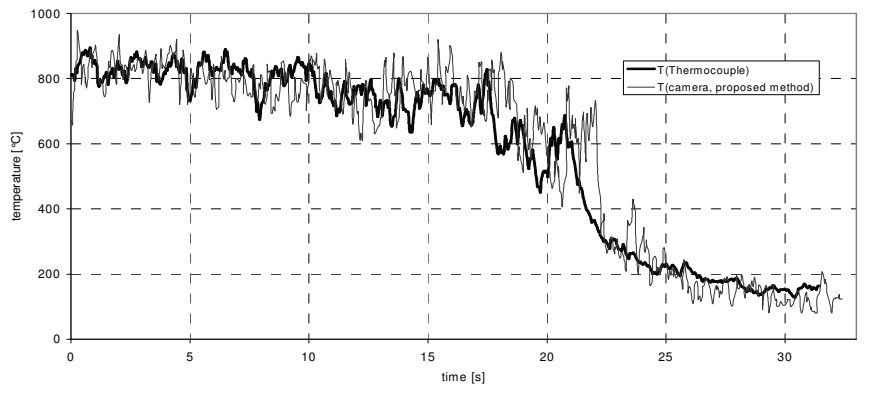

Fig. 11. Temperature measured by thermocouple and infra-red camera for a flame of Pinus pinaster needles at $4 \mathrm{~m}$

a)

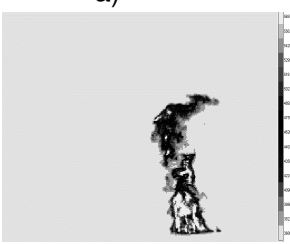

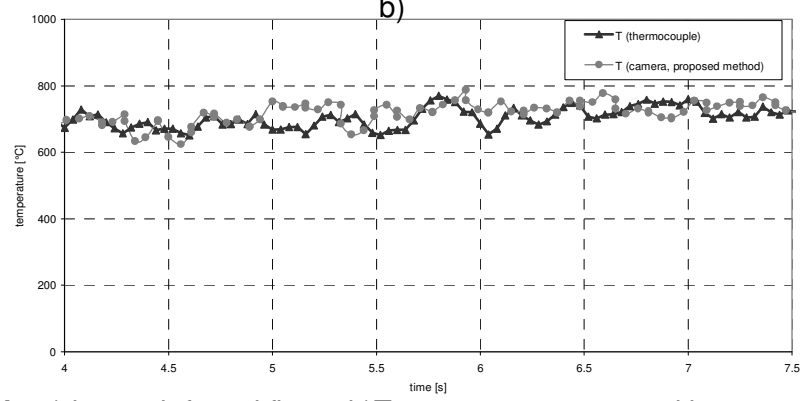

Fig. 12a-b. a) image infrared flame b)Temperature measured by thermocouple and infra-red camera for a flame of Helichrysum italicum at $4 \mathrm{~m}$

a)

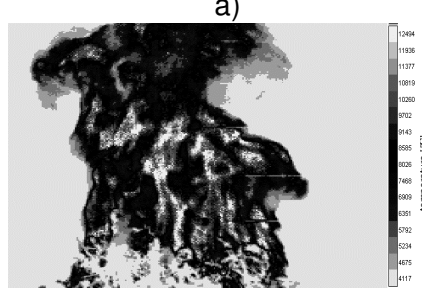

Fig. 13a-b. a) image infrared flame b) Temperature measured by thermocouple and infra-red camera for a flame of Cistus ladaniferus at $2 \mathrm{~m}$

These fuels were selected because they are aromatic plants "regularly" involved during the fire season in Corsica. The infra-red camera with filter $4.2 \mu \mathrm{m}$ was located at $2 \mathrm{~m}$ and $4 \mathrm{~m}$ from the fire respectively for the Helichrysum italicum 


\section{http://dx.doi.org/10.21611/qirt.2006.011}

and for the Cistus ladaniferus. The flame heights were approximately $53 \mathrm{~cm}$ and 1.5 $m$ respectively for the first and second case tests. (Figures 11, 12b and 13b) show that the model gives roughly good results for different distances camera-flame during the flaming and cooling stages. In spite of the fuel change, the model of temperature conversion remains reliable with the parameters being unchanged. The decrease of the temperature is provided (figure $13 \mathrm{~b}$ and 11 ).

\subsection{Temperature measurement in a spreading fire front by infra-red camera}

In this study, we will use three combustibles Pinus pinaster needles. The experimental conditions are unchanged, except the infra-red camera is placed at $\mathrm{m}$. An infra-red image of the flame of is presented in the (figure 14a). The results are presented in the (figure 14b).

a)

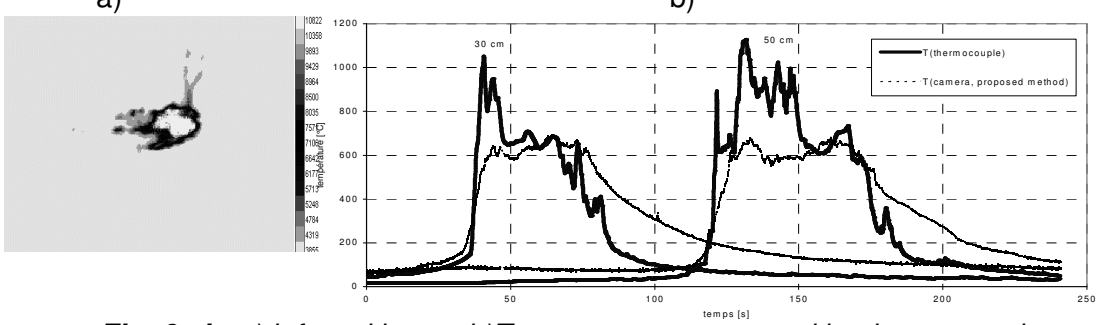

Fig. 6a-b. a) infrared image b)Temperatures measured by thermocouples and infra-red camera at $30 \mathrm{~cm}$ and $50 \mathrm{~cm}$ away from the ignition line at $3 \mathrm{~m}$.

We note that there is a shift in the zone of cooling between the temperature measured by thermocouple and the temperature converted by infra-red camera. This is due to the experimental device. For the experiments of propagation, we use plates of syporex because they resist heat. The infra-red camera films the fuel bed. When this last is flaring, the plates are burning and store the heat. The infra-red camera films embers but also the plates. The experimental temperature is measured by thermocouples placed in the litter. When the latter is burned, the thermocouples are not in contact with embers.

In abstract, in the zone of cooling the difference between the experimental temperature and the converted temperature is due to the cooling of the plates. The comparison of the temperature in the zones of pre-heating and combustion gives very good results. In the zone of combustion we note that certain peaks of temperatures are badly translated by our model. The thermocouples are placed in the litter. At the time of the propagation the needles touch the end of the exposed junction of the thermocouple what distorts the temperature measurement slightly. That does not serious problem for our study because our goal is to translate the phenomenon of propagation as a whole.

\section{Conclusion}

We note that the model suggested in this article gives similar results to that proposed in the literature, by using a lower number of parameters. This step is valid whatever the configuration of the infra-red camera (filter, time integration) with the proviso of determining the parameters a and $N_{0}$. A preliminary stage was to convert the numerical levels into temperatures by using a black body type. This stage, enabled us to test the effectiveness of our model and to validate it. If at the time of the temperature measurement of a flame, the camera is placed at less than $50 \mathrm{~cm}$ of this one, the flow received by the infra-red camera is very important, which causes a saturation. However if the infra-red camera is placed sufficiently far from the flame, 
the flow received by the latter is insufficient the temperature measurement is essential for the determination of the parameters of our model semi-physics simplified [1], this is why, various tests were carried out. For the ethanol flame, in fact the frequencies of pulsation are very well found. For a static flame and a homogeneous bed of pine needles the tendency is always found. These tests were carried out for a distance camera-flame fixed. The use of the infra-red camera for fires of ground, requires an identification of the parameters a and $N_{0}$, however the knowledge of the temperature is essential. An evolution of the laws was thus presented. The evolution of these parameters is very simple: the parameter $N_{0}$ can be assimilated to a constant and parameter a decreases according to the distance. We obtained very correct results. By using ethanol and the needles pine fuel, no deficiency of the proposed model was noted. To validate our model, the vegetable fuel was changed. For this study, Cistus ladaniferus and Helichrysum italicum in Corsica subsp. italicum were selected. These aromatic plants were selected bus in Corsica at the time of the fires, they are the touched first. The results are very satisfactory. The couple of parameters $\left(\mathrm{a}, N_{0}\right)$ was unchanged at the time of the conversion of the numerical levels into temperatures in various positions in the flame. The prospects for this work are numerous in particular the use of the infra-red camera for fires of ground, this study is already undertaken by our laboratory [12].

\section{REFERENCES}

[1] F. Morandini, A. Simeoni, P.A. Santoni, and J.H. Balbi, A model for the spread of fire across a fuel-bed incorporating the effects of wind and slope, Combustion science and technology, (2005, sous presse).

[2] J.L. Dupuy, Mieux comprendre et prédire la propagation des feux de forêt: expérimentation, test et proposition de modèle, Thèse de doctorat de l'Université de Lyon (1997).

[3] R.O. Weber, Toward a comprehensive widfire spread model, Int. J. Wildland Fire, 1 (1991), 245-248.

[4] F. Morandini, P.A. Santoni, and J.H. Balbi, The contribution of radiant heat transfer to laboratory-scale fire spread under the influences of wind and slope, Fire Safety J., 36 (2001), 519-543.

[5] D. Pajani, Thermographie infrarouge quelle longueur d'onde choisir 1 ?, Techniques d'applications MESURES, 52 (1987), 71-76.

[6] A. Arconada, A. Argiriou, F. Papini, and R. Pasquetti, la mesure en thermographie infrarouge : calibration et traitement du signal, journal of modern optics, 34 (1987), 13271335.

[7] D. Pajani, Mesures de températures par caméra infrarouge quelques précautions à prendre, Techniques d'applications MESURES, (1984) 35-41.

[8] D. Balageas, A. Deom and D. Boscher, La mesure de température par camera infrarouge, journée d'étude: mesure des températures, Revue Pratique de Contrôle Industriel, 164 (1990),:61-74.

[9] P.A. Santoni, T. Marcelli, and E. Leoni, Measurement of fluctuating temperatures in a continuous flame spreading across a fuel bed using a double thermocouple probe, Combustion and Flame, 131 (2002); 47-58.

[10] B. Porterie, D. Morvan, J.C. Loraud and M. Larini, fire spread through fuel beds: modelling of wind-aided fires and induced hyyodynamics, Physics of fluids, 12 ( 2000), 1762-1872.

[11] A. Bianchini A, P. Tomi, J. Costa, and A.F. Bernardini, Composition of Helichrysum italicum (Roth) G. Don fil. Subsp. Italicum essential oils from Corsica (France). flavour and fragrance journal, (2001) 16-30.

[12] P.A. Santoni, J.H. Balbi, F. Bosseur, E. Innocenti, T. Marcelli, F. Morandini, F. Nasica, A. Pieri, F. Rinieri, J.L. Rossi, L. Rossi, X. Silvani, and A. Simeoni, Metrology of windland fire: Characterization of a fire spreading across the Corsican scrub., Congrès Environnement et Identité en Méditerranée, Université de Corse, (2004), 1-8. 